\title{
REVIEW
}

\section{Vitamin D in critically ill patients - from molecular damage interactions to clinical outcomes benefits. When, why, how?}

\author{
Alida Moise \\ Anesthesia and Intensive Care Unit, „Prof. Dr. D. Gerota” Hospital, Bucharest, Romania \\ Correspondence to: \\ Alida Moise, PhD, Chief of Anesthesia and Intensive Care Unit, „, Prof. Dr. D. Gerota” Hospital \\ Profesional address: „Prof. Dr. D. Gerota” Hospital, no 29-31 V.V. Stroiescu Street, Bucharest 21392, \\ Bucharest, Romania \\ E-mail: alidamoise@gmail.com
}

\section{Conflicts of interests \\ Nothing to declare}

\section{Acknowledgment}

None

Funding: This research did not receive any specific grant from funding agencies in the public, commercial or not-for profit sectors.

Keywords: Vitamin D; effect; cognition; delirium; obesity.

These authors take responsibility for all aspects of the reliability and freedom from bias of the data presented and their discussed interpretation.

Central Eur J Clin Res 2018;1(1):59-66

Received: 15.07.2018; Accepted: 11.08.2018; Published: 05.09.2018

Copyright @ 2018 Central European Journal of Clinical Research. This is an open-access article distributed under the Creative Commons Attribution License, which permits unrestricted use, distribution, and reproduction in any medium, provided the original work is properly cited.

\section{Abstract}

Vitamin D - „the sunshine vitamin” is essential for the good functioning of the human body. The most important forms of the vitamin $\mathrm{D}$ are the vitamin D2 and the vitamin D3, both biologically inactived. Vitamin D can come from: diet or nutritiv suplimentts and skin. The activation of vitamin $D$ is effect in two steps to the physiologically active 1,25-dihydroxyvitamin D $\left[1,25(\mathrm{OH})_{2} \mathrm{D}\right]$.

The biological actions of Vitamin $\mathrm{D}$ involve regulation of gene expression at the transcriptional level and are mediated through binding to a Vitamin D Receptor (VDR). Vitamin D has multiple roles: hormonale/ nonhormonale, skeletale/nonscheletale, genomice/nongenom- ice. Interesting is inversely corelation between Vitamin D and total body fat (BMI) and correlation between Vitamin $D$ and cognitive impairment, especially Alzheimer Disease or delirium during hospitalisation.

The curent recomandations regarding the supplying with Vitamin D are different for regions of the globe, also differ depending on the baseline serum Vitamin $D$ and on the desired effect. So, potential nonskeletal effects occur at levels $>30 \mathrm{ng} / \mathrm{ml}$, above $50-75 \mathrm{ng} / \mathrm{ml}$, serum level who should become the target of the supplementation. The loading dose should be considered perioperatively for rapid effects.

In conclusion, Vitamin $D$ is more than just a vitamin. It is a substance with multiple roles in body's economy, and in recent years there has been an interest in the relation be- 
tween vitamin $D$ deficiency and obesity or cognitive impairment. The majority of the data supports association, not causation, of low vitamin $D$ levels. In other words, much of data does not clearly support the idea that vitamin D supplementation in a patient with low vitamin $D$ levels reduces the risk of these diseases. But, the supplimentation is very easy and no harm might be done.

\section{Introduction}

Vitamin D is also called „the sunshine vitamin". It is essential for the good functioning of the human body. In the history of Vitamin D there also is a Nobel Premium. It was won by Adolf Windause for chemestry in 1928 "for his studies on the constitution of the sterols and their connection with vitamins". Where does this name come from, why was this vitamin called the vitamin $D$ in 1922? Simple, because there already existed vitamins with the names: $A, B, C$ so the only letter that was not taken was $D$ [1].

\section{Forms}

The vitamin $D$ is actually a group of some vitamins, that are soluble in fat (Vitamins D1-D5), also called seco-steroisis. The most important forms of the vitamin D are the vitamin D2, discovered in 1932 and the vitamin D3, discovered in 1936. Both forms function as prohormones and are considered biologically inactived [2-4].

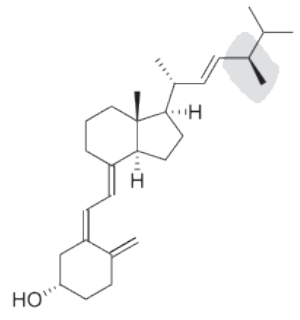

Ergocalciferol (Vitamin D2)

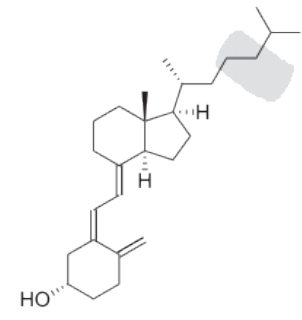

Cholecalciferol (Vitamin D3)
Figure 1. The most important forms of Vitamin D

\section{Sources of Vitamine D}

Vitamin D can come from:

1.diet (fatty fish like salmon, sardines, tuna and eel; fish oils like cod liver oil; mushrooms and eggs, milk and products of milk, cereals, bread, pastele, butter, margarine and oil) or nutritiv suplimentts.

Some countries, like the USA, add vitamin D to foods like milk, soy milk, yogurt, butter, cheese,cereal grains and beer [3].
2. skin, through photochemical synthesis - the major natural source of the vitamin. It is dependent on moderate sun exposure to the face, arms and legs, averaging 5-30 minutes twice per week (UVB light between 270 and $300 \mathrm{~nm}$ ). These wavelengths are present when the UV index is greater than 3. At angles greater than $45^{\circ}$ above the horizon (at sea level), vitamin $\mathrm{D}$ production will be occurring, although some recent research suggests that vitamin $D$ production may occur at angles as low as $30^{\circ}$.

The production of vitamin $D$ in the skin depends on:

- the season of the year,

- the latitude,

- use of sunscreen,

- clothing,

- amount of skin exposed,

- age - synthesis of vitamin D declines with increasing age, due in part to a fall in 7-dehydrocholesterol levels and due in part to alterations in skin morphology [5],

- the amount of melanin in their skin darker skin requires longer than fair skin.

It is thought that as little as five minutes per day of incidental sun exposure is sufficient for the production of Vitamin D, for someone who burns easily, and up to 20 minutes is sufficient for a person with darker skin $[4,15]$.

In the skin (derm), photochemically, non-enzimatic, into thermal isomerization of 7-dehydrocholesterol to previtamin D3, inactive biologycal which is then rapidly converted to vitamin D3 (cholecalciferol) by temperature- and membrane-dependent processes, but excessive exposure to sunlight degrades previtamin D2 and vitamin D3 into inactive photoproducts $[12,15]$.

\section{Metabolism of Vitamin D}

Dietary vitamin $D$ (either $D_{2}$ or $D_{3}$ ) is absorbed with other dietary fats in the small intestine via chylomicrons. Its absortion is dependent on the presence of fat in the lumen, which triggers the release of bile acids and pancreatic lipase with the formation of lipid-containing micelles, which diffuse into enterocytes.

Vitamin $D$ enters the circulation from the lymph or from the skin, it is prelucrated by the liver or storage tissues within a few hours. The activation of vitamin $D$ is effect in two steps:

- the first step occurs in the liver and converts previtamin D to 25-hydroxyvitamin D [25(OH)D], calcidiol, also biologically inactive form. This etape is mediated by the 25-hydroxylase (cytochrome P450 enzyme 2R1 - CY$\mathrm{P} 2 \mathrm{R} 1$ ). $25 \mathrm{OH}-\mathrm{D}$ is the major circulating form of 
vitamin D [15]; it circulates bound to a specific plasma carrier protein, Vitamin D Binding Protein (DBP). DBP also transports vitamin $D$ and its metabolits $[6-8,14,15]$.

-the second step occurs primarily in the kidney and forms the physiologically active 1,25-dihydroxyvitamin $\mathrm{D}\left[1,25(\mathrm{OH})_{2} \mathrm{D}\right]$, calcitriol, mediated by 1a-hydroxylase (CYP27B1) $[4,8,10,15]$ and regulated by serum phosphorus, calcium and itself, as by fibroblast growth factor 23 (FGF-23), parathormone (PTH) with up-regulation and down-regulation via fibroblast-like growth factor-23. The 1a-hydroxylase gene is also expressed in several extra-renal tissues, but its contribution to calcitriol formation in these tissues is unknown. CYP27B1 is also expressed extrarenally in bone, placenta, prostate, keratinocytes, macrophages, T-lymphocytes, dendritic cells, several cancer cells, and the parathyroid gland and enables the production of $1,25(\mathrm{OH})_{2} \mathrm{D}$. This active form of vitamin $\mathrm{D}$ is locally active and exerts auto- or paracrine effects [8-12].

Serum albumin and serum DBP (D-binding protein) are the principal carriers of vitamin $\mathrm{D}$ and its metabolits. The affinity of albumin for $25(\mathrm{OH})$ Vitamin $D$ is substantially lower than that of DBP. DBP have the important role by actively facilitating the acquisition of $25(\mathrm{OH})$ $\mathrm{D} / 1,25(\mathrm{OH})_{2} \mathrm{D}$ or by defining the amount of 'free vitamin D' that is available for passive cellular uptake $[14,18]$.

Excess fat-soluble vitamins D2, D3 after 24 hours are stored in the liver and fatty tissue for approximately two months. Adipose tissue as the primary site of vitamin $D$ accumulation and there was enhanced uptake and clearance of vitamin $D$ by adipose tissue in obese subjects compared with those of normal weights. Adipose tissue stores of vitamin $D$ probably represent "non-specific" stores sequestered because of the hydrophobic nature of vitamin $D$, but the extent to which the processes of accumulation or mobilization are regulated by normal physiological mechanisms remains unknown at this time [4].

When the body needs more vitamins, vitamin D-2 and vitamin D-3 are converted to their active 25-hydroxyvitamin D. The released 25-hydroxyvitamin $D$ can circulate in the body for approximately three weeks. After the body is replenished, the biologically active form is stored in fat tissues for months; 25-hydroxyvitamin $D$ is released from the storage irregularly depending on the body's need. By the time the physician detects vitamin $D$ deficiency, serum concentration of 25-hydroxyvitamin $D$ is less than $20 \mathrm{ng} / \mathrm{ml}$. At this point, vitamin $D$ stores have been depleted [4].

\section{Normal serum level and deficiency}

Laboratory measures 25(OH)D concentration, that is consideret the functional indicator of vitamin D status $[16,20]$.

The interpretation of vitamin $D$ levels varies in literature: some consider the deficiency is $<25-30 \mathrm{ng} / \mathrm{ml}$, others think that Vitamin $D$ deficiency is diagnosed when 25(OH)D $<20 \mathrm{ng} /$ $\mathrm{mL}$, and vitamin $\mathrm{D}$ insufficiency is defined as 25(OH)D of 21-29 ng/mL [20].

For endocrinologists the value for $25(\mathrm{OH})$ Vitamin D more $30 \mathrm{ng} / \mathrm{mL}$ is considered sufficient, with $40-60 \mathrm{ng} / \mathrm{mL}$ being the preferred range.

Vitamin $\mathrm{D}$ intoxication usually doe not occur until $25(\mathrm{OH}) \mathrm{D}>150 \mathrm{ng} / \mathrm{mL}$ and results only from the excessive consumption of supplements with hypercalcaemia $[15,20]$.

The clinical practice corellates the level of Vitamin D with its effects. The threshold for normality should probably be the serum $250 \mathrm{OD}$ required for maximum suppression of parathyroid hormone, greatest calcium absorption and highest bone mineral density [41].

\section{Effects of Vitamin D}

The biological actions of calcitriol involve regulation of gene expression at the transcriptional level and are mediated through binding to a Vitamin D Receptor (VDR), a specific zinc-finger nuclear receptor superfamily of steroid/thyroid hormone receptors, located primarily in the nuclei of target cells, and regulates expression of up to 2000 genes, directly or indirectly [15].

VDR is present in most tissues and cells in the body, allowing it to do her roles:

- jejunum and ileum (increases absortion of calcium and magnesium),

- bone (role in the mineralization),

- cardiovascular system (endothelium, vascular smooth muscle - may protect against atherosclerosis; cardiomyocytes -inhibition of cell proloferation without apoptosis; promotes cardiomyotube formation, induces cardiac differentiation) [37],

- pancreatic beta cells (mediated by upreglation of insulin receptors and modulates inflamation);

- hepatocytes (down-regulates fibrogenic TGF- $\beta$ signaling, anti-inflamatory effects by inhibiting monocyte activation and TNF- $\alpha$ and IL-1 expression),

- cells of immune system like (acts as an 
immunomodulator: local macrophage synthesis of $1,25(\mathrm{OH}) 2 \mathrm{D}$ is implicate in response to TLR signaling is also a key feature of innate immunity (13), inhibition of production of interleukin by activated T-lymphocytes and of immunoglobulin by activated B-lymphocytes, differentiation of monocyte precursor cells, modulation of cell proliferation, influences several growth factors (IGF-1, TGF $\beta$, MAPK5, NF-Kb [12,13,15,22], -muscle -increases protein synthesis, protects against insulin resistance [37], - skin (antiproliferative, immunosuppresive and prodifferentiating effects),

- adipocytes - inhibits intracellular fat accumulation, enhances basal lipolysis without cell toxicity, upregulation of $\beta$-oxidation-related genes, lipolytic enzymes and vitamin D-responsive genes [37].

- selected cancer cells - antiproliferative, prodifferentiating, increases apoptosis, decreases angiogenesis: date for renal carcinoma, thyroid, breast, colon, neural cells and prosthat - the nonhormonal, intracrine, and paracrine actions of 1-hydroxylated vitamin $D$ metabolites in man [8, 9,13,21,29,37].

The clasification of the roles:

- hormonale/ nonhormonale,

- skeletale/nonscheletale,

- genomice/nongenomice (mediated through the VDR transcriptional effects inside the cell nucleus / VDR induces rapid signaling, situated on the cell membrane and/or cytoplasm, via calcium) $[15,21,22]$.

A large number of cellular processes are regulated by calcium - as a primary signaling pathway or it can operate as a modulator signal.

- in non-excitable cells - fertilization, proliferation, metabolism, secretion and smooth muscle contraction.

- in excitable cells- contraction in the heart or memory formation in neurons.

- a modulator signal that can induce subtle changes in the generation and function of this primary Ca2+ signal: Alzheimer's disease (AD) and cardiovascular disease.

Beside its role in homeostasia of the calcium, Vitamin D has a role in regulating cell proliferation and differentiation, in insulin resistence, obesity, metabolic syndrom and various cancers. Also vitamin D possess antiproliferative, pro-apoptotic and immunomodulatory effects in cancer $[8,15]$. For non-hormonal roles of vitamine $D$, the regulation is a lot more sensitive. There is the association between the deficience of vitamin $D$ and many acute and chronic illnesses including disorders of calcium metabolism, autoimmune diseases (multiple sclerosis, rheumatoid arthritis, etc), some cancers (breast, colon, prosthat), type 2 diabetes mellitus, respiratory, cardiovascular disease and infectious diseases (tuberculosis, influenza, viral), but not it is not proven enough yet. [15]. Also, Vitamin D supplementation seemed to decrease general mortality in elderly people [23].

The majority of the data supports association, not causation, of low vitamin D levels.

\section{Obesity and Vitamin D}

Interesting is inversely corelation between total body fat ( BMI) and 25-OH-D levels. More often in individuals who are not obese, body size and adiposity are inversely associated with blood $25(\mathrm{OH}) \mathrm{D}$ concentrations. BMI is inversely associated with the increase in serum $25(\mathrm{OH}) \mathrm{D}$ levels in response to vitamin D supplementation [24-28]. tamin D:

Ipoteses for corelation BMI- level of vi-

- may be due to the increased metabolic clearance of vitamin $D$ through enhanced uptake in fat tissue and/or the decreased bioavailability of vitamin $D$ once it is deposited in the fat tissue;

- to storage of vitamin $D$ in fat - The concept of storage of vitamin $D$ in the adipose tissue has gained recent popularity and some studies recommend a higher intake of vitamin D in obese women, however there are no longitudinal studies to supports that suggestion.

- sedentary lifestyle, low sunlight exposure,

- true vitamin D deficiency - genetic changes in vitamin $\mathrm{D}$ metabolism

- diet

- other unknown factors [15,16,19,24-28]

But, more trials did not show significant change in total body fat mass after treatment with vitamin D [28].

\section{Cognition and Vitamin D}

The most of important correlation is between Vitamin $\mathrm{D}$ and cognitive impairment, because the impact on human society and because of validation of the information available on this subject.

Boston, hosted in July 2013 the meeting of the international experts at the invitational summit on „Vitamin D and cognition in older adults". Based upon literature and expert opinion, the task force focused on key questions on the role of vitamin $D$ in Alzheimer disease (AD) and related disorder. Each question was discussed and voted using a Delphi-like approach [29]. 
Conclusions were:

- hypovitaminosis $D$ increases the risk of cognitive decline and dementia in older adults,

- not be used thus far as a diagnostic or prognostic biomarker of Alzheimer disease due to lack of specificity and insufficient evidence,

-hypovitaminosis D should be screened in this population because of its high prevalence and supplemented, if necessary, but this advice was not specific to cognition.

There is a site dedicated to Vitamin D with information about this vitamin:

Vitamin D. There are a lot of articles for Vitamin $\mathrm{D}$ and congnition on the site.

A significant association between $A D$ and low levels of vitamin $D$ has been demonstrated. The rol of vitamin D in AD are: expression,

- regulating calcium-sensing receptor

- enhancing amyloid- $\beta$ peptides clearance,

- downregulating matrix metalloproteinases,

- upregulating heme oxygenase 1 ,

- suppressing the reduced form of nicotinamide adenine dinucleotide phosphate expression.

Furthermore, vitamin D supplements appear to have a beneficial clinical effect on $A D$ by:

- regulating micro-RNA,

- enhancing toll-like receptors,

- modulating vascular endothelial factor expression,

- modulating angiogenesis,

- regulating calcium-sensing receptor expression,

- enhancing amyloid- $\beta$ peptides clear-

ance,

- down regulating matrix metalloproteinases,

- up regulating heme oxygenase 1 ,

- suppressing the reduced form of nicotinamide adenine dinucleotide phosphate expression [30].

The results of a meta-analysis revealed that subjects with deficient vitamin $D$ status $(25(\mathrm{OH}) \mathrm{D}$ level $<50 \mathrm{nmol} / \mathrm{L})$ were at increased risk of developing $A D$ by $21 \%$ compared with those possessing 25(OH)D level > $50 \mathrm{nmol} / \mathrm{L}$ [31].

Time of progression to severe stage of Alzheimer's disease was slower in patients under treatment with vitamin $\mathrm{D}$ compared with those without treatment $(5.4 \pm 0.4$ years vs. 4.4 \pm 0.16 years respectively, $p=0.003$ ) [32] .

Similarly, the risk of cognitive impairment was up to four times bigger in the severely deficient elders $(25(\mathrm{OH}) \mathrm{D}<25 \mathrm{nmol} / \mathrm{L})$ in comparison with individuals with adequate levels (75 nmol/L) [33].

There are functional explications: neurosteroid properties of vitamin D. The effects of Vitamin D are exercised through its nuclear hormone receptor the VDR, which is expressed in neuronal and glial cells in almost all regions of the CNS, and in special in the hippocampus, hypothalamus, cortex and subcortex, the areas essential for cognition. The active form of vitamin $D$ has a trophic function of neuronal differentiation and maturation via control of the synthesis of neurotrophic agents such as nerve growth factor (NGF) and glial cell line-derived neurotrophic factor (GDNF). Moreover, 1,250HD regulates the genetic expression of numerous neurotransmitters in the brain, including acetylcholine, dopamine, serotonin and c-aminobutyric acid, notably in the hippocampus [34,40].

The vitamin $D$ is unregulator of neuroprotection, antiepileptic and anticalcification effects, neuro-immunomodulation, interplay with neurotransmitters and hormones, modulation of behaviors, brain ageing, and some other, less-explored, brain processes [35].

The activities of vitamin $D$ for consolidation of cognitive may represent primary effects in the brain rather than, secondary systemic effects given the expression of vitamin $D$ receptors in the brain, and Vitamin $D$ can prevent neuronal damage through the neurotrophic factor and through the process of detoxification. It also contributes to regulating behaviour and protecting the brain through an antiinflammatory anti-oxidant buffer [36].

Moreover, for clinical, there are the speculation that vitamin $D$ may thus play a role in protecting the brain from delirium. So, Vitamin D promotes neuroprotection by modulating the production of choline acetyltransferase. Choline acetyltransferase is the key enzyme in biosynthesis of acetylcholine and cholinergic deficits are implicated in delirium. In addition, Vitamin D may contribute to neuroprotection by modulating the production of glial cell-derived neurotrophic factor, NO synthase [38-40].

Vitamin D status before hospitalisation is associated with the risk of delirium, a problem of great interest in this moment. The level of pre-hospital $25(\mathrm{OH}) \mathrm{D}<10 \mathrm{ng} / \mathrm{ml}$ is indeed associated with a significant increase in the odds of delirium in patients during hospitalisation but future studies need to complete this information [40].

In a recent study, the low level of vitamin $D$ has been associated with an increased risk of elderly patients developing cognitive impairment in postoperative [43]. 


\section{Vitamin D supplementation}

The curent recomandations regarding the supplying with Vitamin $D$ are different for regions of the globe. These recommendations also differ depending on the baseline serum Vitamin $D$ and on the desired effect $[16,42]$.

So, potential nonskeletal effects occur at levels $>30 \mathrm{ng} / \mathrm{ml}$, above $50-75 \mathrm{ng} / \mathrm{ml}$, serum level who should become the target of the supplementation.

There are on the web site of The Endocrine Society the following schemes:

- 400-600ui/day for children (0-18y) with skeletal effects, but not known clear at this time what are potential nonskeletal health benefits. For a level of Vitamin $D>30 \mathrm{ng} / \mathrm{ml}$ are require at least $1000 \mathrm{lU} / \mathrm{d}$.

- $600 \mathrm{lU} / \mathrm{d}$ for 19-50y. For a level of Vita$\min \mathrm{D}>30 \mathrm{ng} / \mathrm{ml}$ are require at least $1500-2000$ IU/d.

- 800IU/d for $>50 y$, also for a level of Vitamin $\mathrm{D}>30 \mathrm{ng} / \mathrm{ml}$ are require at least 1500 $2000 \mathrm{IU} / \mathrm{d}[20,27]$.

There are special situations when if vitamin $D$ is given at least two to three times more for their age group:

- obese children and adults

- children and adults on anticonvulsant medications, glucocorticoids, antifungals such as ketoconazole, and medications for AIDS.

The administration of big doses suggest that the maintenance tolerable upper limits of vitamin $D$, which is not to be exceeded without medical supervision is $4000 \mathrm{IU} / \mathrm{d}$ for anyone over 8 yr [20].

Also, there are high variability in response to a given dose of vitamin $D$ supplementation $[16,17,18]$. The higher doses vitamin D3 supplementation can not always increases the serum level upper $50 \mathrm{ng} / \mathrm{ml}$, the baseline serum being very important. Therefore, for all adults who are vitamin $\mathrm{D}$ sever deficient and for rapid effects is recommeanded be treated with loading doses $\left(50,000 \mathrm{IU}\right.$ of vitamin $\mathrm{D}_{2}$ or vitamin $D_{3}$ once a week for 8 wk or its equivalent of 7,000 IU of vitamin $D_{2}$ or vitamin $D_{3}$ daily) to achieve a blood level of 25(OH)D above $30 \mathrm{ng} /$ $\mathrm{ml}$, followed by maintenance therapy of 1500 $2000 \mathrm{IU} / \mathrm{d}[20,42]$.

We strongly believe that the loading dose should be considered for rapid correction of the deficiency of Vitamin $D$, especially perioperatively or in all oxidative stress situations. More like a concentration below $50 \mathrm{nmol} / \mathrm{L}$ for $25(\mathrm{OH}) \mathrm{D}$ was an independent and significant risk factor for delirium (odds ratio $=2.7 ; 95 \%$ confidence interval: $1.04-7.2, \mathrm{P}=0.04$ ) in a multivariate regression analysis adjusted for all registered confounders at hip fracture patients in postoperative [44]. Also, Vitamin D is ,essential for both optimal nerve function and recovery following stress" [40]. But, although the loading doses administered perioperatively seem attractive, association between rapid improvement of vitamin D status and the incidence of the delirium should be verified in future studies.

At this time, for prevention of cognitive diseases the recommandation is 4000-5000 $\mathrm{IU} / \mathrm{d}$ and for Alzheimer's desease 4,000 IU/d of vitamin D [45].

\section{Conclusion}

Vitamin $D$ is more than just a vitamin. It is a substance with multiple roles in body's economy, and in recent years there has been an interest in the relation between vitamin $D$ deficiency and obesity or cognitive impairment.

The majority of the data supports association, not causation, of low vitamin $\mathrm{D}$ levels. In other words, much of data does not clearly support the idea that vitamin $D$ supplementation in a patient with low vitamin $D$ levels reduces the risk of these diseases.

But, the supplimentation is very easy and no harm might be done.

\section{References}

1. Wolf G. The Discovery of Vitamin D: The Contribution of Adolf Windaus. J Nutr 2004;134(6):1299-302

2. Bover J, Egido J, Fernández-Giráldez E, Praga M, Solozábal-Campos C, Torregrosa $\mathrm{JV}$, et al. Vitamin D, vitamin D receptor and the importance of its activation in patients with chronic kidney disease. Nefrologia 2015;35(1):28-41

3. Thacher TD, Fischer PR, Pettifor JM. Vitamin $D$ treatment in calcium-deficiency rickets: a randomised controlled trial. Arch Dis Child 2014;99(9):807-11

4. Cranney A, Horsley T, O'Donnell S, Weiler $H$, Puil $L$, Ooi $D$, et al. Effectiveness and safety of vitamin $\mathrm{D}$ in relation to bone health. Evid Rep Technol Assess (Full Rep) 2007;(158):1-235

5. Laughlin JM, Holick MF. Aging decreases the capacity of human skin to produce vitamin D3. J Clin Investigation 1985;76(4):1536-1538

6. Strushkevich N, Usanov SA, Plotnikov AN, Jones G, Park HW. Structural analysis of CYP2R1 in complex with vitamin D3. Jour- 
nal of Molecular Biology 2008;380(1):95106

7. Al Mutair AN, Nasrat GH, Russell DW. Mutation of the CYP2R1 vitamin D 25-hydroxylase in a Saudi Arabian family with severe vitamin D deficiency. J Clin Endocrinol 2012;97(10):E2022-5.

8. Urbschat $A$, Paulus $P$, von Quernheim QF, Brück P, Badenhoop K, Zeuzem S, et al. Vitamin D hydroxylases CYP2R1, CYP27B1 and CYP24A1 in renal cell carcinoma. Eur J Clin Invest 2013;43(12):1282-90

9. Penna-Martinez M, Ramos-Lopez E, Stern $\mathrm{J}$, Kahles H, Hinsch N, Hansmann ML, et al. Impaired vitamin $\mathrm{D}$ activation and association with CYP24A1 haplotypes in differentiated thyroid carcinoma. Thyroid 2012;22(7):709-16

10 Sakaki T, Kagawa N, Yamamoto K, Inouye $\mathrm{K}$. Metabolism of vitamin D3 by cytochromes P450. Front Biosci 2005;10:119-34

11. Quarles LD. Endocrine functions of bone in mineral metabolism regulation. Journal of Clinical Investigation 2008;118(12):3820-8

12. Adams JS, Hewison M. Update in vitamin D. J Clin Endocrinol Metab 2010;95:471-478

13. Hewison M. Vitamin D and innate immunity. Curr Opin Investig Drugs 2008;9:485-490

14. Chun RF, Adams JS, Hewison M. Back to the future: a new look at 'old' vitamin D. J Endocrinol 2008;198:261-26

15. Wacker M, Holick MF. Vitamin D - effects on skeletal and extraskeletal health and the need for supplementation. Nutrients 2013;5:111-148

16. Zhou $Y$, Zhao LJ, Xu X, Ye A, Travers-Gustafson D, Zhou B, et al. DNA methylation levels of CYP2R1 and CYP24A1 predict vitamin $\mathrm{D}$ response variation. J Steroid Biochem Mol Biol 2014;144:207-14

17. Wagner D, Hanwell HE, Schnabl K, Yazdanpanah M, Kimball S, Fu L, et al. The ratio of serum 24,25-dihydroxyvitamin $\mathrm{D}(3)$ to 25-hydroxyvitamin $\mathrm{D}(3)$ is predictive of 25-hydroxyvitamin $D(3)$ response to vitamin $D(3)$ supplementation. J Steroid Biochem Mol Biol 2011;126(3-5):72-7

18. Fu L, Yun F, Oczak M, Wong BY, Vieth R, Cole DE. Common genetic variants of the vitamin $\mathrm{D}$ binding protein (DBP) predict differences in response of serum 25-hydroxyvitamin $\mathrm{D}[25(\mathrm{OH}) \mathrm{D}]$ to vitamin $\mathrm{D}$ supplementation. Clin Biochem 2009;42(1011):1174-7

19. Blum M, Dallal GE, Dawson-Hughes B. Body size and serum 25 hydroxy vitamin $D$ response to oral supplements in healthy older adults. J Am Coll Nutr 2008;27(2):274-9
20. Holick MF, Binkley NC, Bischoff-Ferrari HA, Gordon CM, Hanley DA, et al. Evaluation, treatment, and prevention of vitamin $D$ deficiency: An endocrine society clinical practice guideline. J Clin Endocrinol Metab 2011;96:1911-1930

21. Trochoutsou Al, Kloukina V, Samitas K, Xanthou G. Vitamin-D in the Immune System: Genomic and Non-Genomic Actions. Mini Rev Med Chem 2015;15(11):953-63

22. Hewison M. An update on vitamin $D$ and human immunity. Clin Endocrinol (Oxf) 2012;76(3):315-25

23. Bjelakovic G, Gluud LL, Nikolova D, Whitfield K, Wetterslev J, Simonetti RG, et al. Vitamin D supplementation for prevention of mortality in adults. Cochrane Database Syst Rev 2014;(1):CD007470

24. Seo JA, Eun CR, Cho H, Lee SK, Yoo HJ, Kim SG, et al. Low vitamin D status is associated with nonalcoholic Fatty liver disease independent of visceral obesity in Korean adults. PLoS One 2013;8(10):e75197

25. Bhatt SP, Nigam P, Misra A, Guleria R, Qadar Pasha MA. Independent associations of low 25 hydroxy vitamin D and high parathyroid hormonal levels with nonalcoholic fatty liver disease in Asian Indians residing in north India. Atherosclerosis 2013;230(1):157-63

26. Saliba W, Barnett-Griness O, Rennert G. The relationship between obesity and the increase in serum 25(OH)D levels in response to vitamin D supplementation. Osteoporos Int 2013;24(4):1447-54

27. Shab-Bidar S, Bours S, Geusens PP, Kessels AG, van den Bergh JP. Serum 25(OH) $D$ response to vitamin D3 supplementation: a meta-regression analysis. Nutrition 2014;30(9):975-85

28. Gallagher JC, Yalamanchili V, Smith LM. The effect of vitamin $D$ supplementation on serum 25(OH)D in thin and obese women. J Steroid Biochem Mol Biol 2013;136:195200

29. Annweiler C, Dursun E, Féron F, Gezen-Ak $D$, Kalueff AV, Littlejohns T, et al. Vitamin $D$ and cognition in older adults: international consensus guidelines. Geriatr Psychol Neuropsychiatr Vieil 2016;14(3):265-73

30. Lu'o'ng KV, Nguyen LT. The Role of Vitamin $D$ in Alzheimer's disease: Possible Genetic and Cell Signaling Mechanisms. AM J Alzheimer's Disease and Other Dementias 2013;28(2):126-36

31. Shen L, Ji HF. Vitamin D deficiency is associated with increased risk of Alzheimer's disease and dementia: evidence from me- 
ta-analysis. Nutr J 2015;14:76-81

32. Chaves M, Toral A, Bisonni A, Rojas JI, Fernández $C$, Basallo MJ, et al. Treatment with vitamin $D$ and slowing of progression of severe stage of Alzheimer s disease. Vertex 2014;25(114):85-91

33. Soni M, Kos K, Lang IA, Jones K, Melzer $D$, Llewellyn DJ. Vitamin D and cognitive function. Scand J Clin Lab Invest Suppl 2012;243:79-82

34. Annweiler C, Llewellyn DJ, Beauchet $\mathrm{O}$. Low serum vitamin $D$ concentrations in Alzheimer's disease: a systematic review and meta-analysis. J. Alzheimer's Disease 2013;33(3):659-674

35. Kalueff AV, Tuohimaa P. Neurosteroid hormone vitamin $D$ and its utility in clinical nutrition. Curr Opin Clin Nutr Metab Care 2007;10(1):12-19

36. Amraei M, Mohamadpour R, Moayeri A, Abbasi N, Shirzadpour E, Mohamadpour M. Vitamin D and its association with memory and learning: A systematic review and meta-analysis. Biomedical Research 2017;28(17):7427-7433

37. Al-Tarrah K, Hewison M, Moiemen N, Lord JM. Vitamin D status and its influence on outcomes following major burn injury and critical illness. Burns Trauma 2018;6:11

38. Hshieh TT, Fong TG, Marcantonio ER, Inouye SK. Cholinergic deficiency hypothesis in delirium: a synthesis of current evidence. J Gerontol A Biol Sci Med Sci 2008;63(7):764-72

39. Ford J, Hategan A, Bourgeois JA, Tisi DK, Xiong GL. Hypovitaminosis D in Delirium: a Retrospective Cross-sectional Study. Can Geriatr J 2013;16(4):186-191

40. Quraishi SA, Litonjua AA, Elias KM, Gibbons FK, Giovannucci E, Camargo CA, et al. Association between pre-hospital vitamin D status and hospital-acquired new-onset delirium. Br J Nutr 2015;113(11):1753-1760

41. Findlay M, Anderson J, Roberts S, Almond $A$ and Isles $C$. Treatment of vitamin D deficiency: divergence between clinical practice and expert advice. Postgraduate Medical Journal 2012;88(1039):255-260.
42. Shab-Bidar S, Bours SP, Geusens PP, van der Velde RY, Janssen MJ, van den Bergh JP. Suboptimal effect of different vitamin D3 supplementations and doses adapted to baseline serum 25(OH)D on achieved $25(\mathrm{OH}) \mathrm{D}$ levels in patients with a recent fracture: a prospective observational study. Eur J Endocrinol 2013;169(5):597-604

43. Zhang Y, Shan GJ, Zhang YX, Cao SJ, Zhu SN, Li HJ, et al. First Study of Perioperative Organ Protection (SPOP1) Investigators. Preoperative vitamin D deficiency increases the risk of postoperative cognitive dysfunction: a predefined exploratory sub-analysis. Acta Anaesthesiol Scand 2018;62(7):924-935

44. Torbergsne AC, Watne LO, Frihagen F, WyIle TB, Brugaard A, Mowe M. Vitamin deficiency as a risk factor for delirium. European Geriatric Medicine 2015;6(4):314-318

45. Henrikson NB, Morrison CC, Blasi PR, Nguyen M, Shibuya KC, Patnode CD. Behavioral Counseling for Skin Cancer Prevention: Evidence Report and Systematic Review for the US Preventive Services Task Force. JAMA 2018;319(11):1143-1157

\section{Abbreviations}

1,25(OH) $)_{2} \mathrm{D}-1,25$-dihydroxyvitamin $\mathrm{D}$

25(OH)D - 25-hydroxyvitamin D

AD - Alzheimer's disease

BMI - total body fat

CYP2R1- cytocrome P450 enzyme 2R1

CYP27B1- cytocrome P450 enzyme 27B1

DBP - Vitamin D Binding Protein

FGF-23 - fibroblast growth factor 23

GDNF - glial cell line-derived neurotrophic factor

IL-1 - interleukine 1

NGF - nerve growth factor

NO - nitrogen

PTH - parathormone

RNA - ribonucleic acid

TGF- $\beta$-Tumor growth factor $\beta$

TNF- $\alpha$ - tumor necrosis factor $\alpha$

VDR - Vitamin D Receptor

UVB - ultraviolet radiation 